Review Article

\title{
Anatomy of the lacrimal apparatus from a rhinologist's perspective: a review
}

\author{
Manish Munjal ${ }^{1 *}$, Shubham Munjal' ${ }^{2}$ Hitant Vohra², Anu Prabhakar², Ajay Kumar², \\ Sonia Singh ${ }^{2}$, Anshu Soni ${ }^{2}$, Seema Gupta ${ }^{2}$, Meenakshi Agarwal ${ }^{2}$
}

${ }^{1}$ Department of Otorhinolaryngolgy, ${ }^{2}$ Department of Anatomy, Dayanand Medical College, Ludhiana, Punjab, India

Received: 02 December 2020

Revised: 11 January 2021

Accepted: 12 January 2021

\author{
*Correspondence: \\ Dr. Manish Munjal, \\ E-mail: manishmunjaldr@yahoo.com
}

Copyright: (C) the author(s), publisher and licensee Medip Academy. This is an open-access article distributed under the terms of the Creative Commons Attribution Non-Commercial License, which permits unrestricted non-commercial use, distribution, and reproduction in any medium, provided the original work is properly cited.

\begin{abstract}
The postero-superioly situated lacrimal glands secreate tears to lubricate the exposed sclera, limbus and the cornea. The tears are ultimately are channeled into the antero-inferior sited lacrimal sac and thereby into the nasal inferior meatus. Epiphora may be secondary to irritative or obstructive pathology in the naso-lacrimal system. Individual with epiphora necessitates intervention, medical or surgical. The naso-lacrimal system with its unique anatomy has been elaborated upon to assist in detecting the precise site of pathology and plan management likewise.
\end{abstract}

Keywords: Lacrimal galand, Lacrimal sac, Nasolacrimal duct

\section{INTRODUCTION}

\section{The lacrimal apparatus}

The lacrimal apparatus comprises the lacrimal gland, which secretes a complex fluid (tears), and their excretory ducts convey fluid to the surface of the eye, the punctae, canaliculi, lacrimal sac and nasolacrimal duct, by which the fluid is collected and conveyed into the nasal cavity. ${ }^{1}$ The epithelium of the cornea and conjunctiva is of ectodermal origin, as are also the eyelashes and the lining cells of the tarsal, ciliary and other glands, which open on the margins of the eyelids. ${ }^{2}$

\section{REVIEW OF LITERATURE}

\section{Embryology of the lacrimal gland}

The epithelium of the alveoli and ducts of the lacrimal gland arise as a series of tubular buds (usually 8 in number) from the ectoderm of the superior conjunctiva) These buds are arranged in two groups; one forming the gland proper, and the other its palpebral process. The lacrimal sac and nasolacrimal duct are considered to be derived from the ectoderm in the nasomaxillary groove between the lateral nasal prominence and the maxillary prominence. This thickens to form a solid cord of cells, which sinks into the mesenchyme. During the third month the central cells of the cord break down and a lumen is acquired. In this way the nasolacrimal duct is established. The lacrimal canaliculi arise as buds from the upper part of the cord of cells and secondarily establish openings (punctua lacrimalia) on the margins of the lids. The inferior canaliculus cuts off a small part of the lower eyelid to form the lacrimal caruncle and plica semilunaris. The epithelium of the cornea and conjunctiva is of ectodermal origin, as are also the eyelashes and the lining cells of the tarsal, ciliary and other glands, which open on the margins of the eyelids. The accessory lacrimal glands (Krause, Wolfring) probably, develop from an epithelial invagination of the conjunctiva. Tears are not produced until the second or third month after birth. ${ }^{1,2}$

The lacrimal gland is derived phylogenetically from serous secreting glands and those producing oily 
secretions. In primates the lacrimal (serous) element has migrated from its original position in the lower lid to the upper. The human lacrimal gland is superolateral in the orbit and has a large, upper orbital and smaller, lower palpebral part, the two being continuous posterolateral around the concave lateral edge of the levator aponeurosis. The continuity of the two parts is through an opening in the fascial support called the lacrimal foramen.

The orbital part, about the size and shape of an almond, lodges in the lacrimal fossa on the medial aspect of the zygomatic process of the frontal bone, just within the orbital margin. It lies above the levator palpebrae superioris and. laterally, above the lateral rectus. It's inferior aspect is connected to the levator's sheath, its upper to the orbital periosteum; its anterior aspect adjoins the orbital septum and its posterior is attached to the orbital fat. The orbital part of the gland measures about $20 \times 12 \times 5 \mathrm{~mm}$ in the adult and weighs around $0.78 \mathrm{gm}$, two to three times the size of the palpebral portion. The greyish-pink colour of the gland can readily be distinguished from the yellow orbital fat. ${ }^{3}$

The palpebral part, about one-third the size of the orbital, has two or three lobules extending inferior to the levator aponeurosis into the lateral part of the upper lid, where it is attached to the superior conjunctival fornix. It is visible through the conjunctiva when the lid is everted. Its ducts, about 12 in number, open into the superior fornix, those from the orbital part (four or five) passing through the palpebral part to join some of its ducts and the rest (six to eight) opening separately. The ducts then pass through the Muller's muscle and the conjunctiva, and enter the superolateral conjunctival fornix, approximately 4 to $5 \mathrm{~mm}$ above the convex lateral margin of the upper eyelid tarsus. Thus all ducts traverse the palpebral part so that excision of this part is functionally equivalent to the total removal of the gland. ${ }^{1,2}$

Many small accessory lacrimal glands occur in or near the fornices. They are more numerous in the upper lid than in the lower. This may explain why the conjunctiva does not dry up after extirpation of the main lacrimal gland.

The accessory lacrimal glands consist of the glands of Wolfring and Krause, and appear as small lobules within the conjunctival connective tissue (substantia propria) There are some 30 glands of Krause in the upper fornix, and six to eight in the lower fornix. ${ }^{4}$ The accessory glands of Wolfring are less numerous, with just three glands at the superior border of upper tarsus and one at the inferior border of lower tarsus. ${ }^{4}$

The lacrimal gland has no definite capsule but possesses a thin, connective tissue pseudo capsule that is continuous with the tissue between the glandular lobules.
This thin pseudo capsule is clinically distinct and provides an important anatomic landmark in the management of lacrimal tumors. Many fascial strands (inappropriately called ligaments) attach to the lacrimal gland to provide support. The superior transverse ligament of the orbit (Whitnall's ligament) probably provides most of the support to the orbital lobe, along with help of the lateral edge and the horn of the levator aponeurosis. Whitnall's ligament inserts on the superolateral orbital wall and intermingles with the connective tissue of the gland, and connects via a small attachment to the lateral orbital wall. Whitnall ligament is a sleeve of fibrous tissue with both a superior and inferior component which join medially and laterally before inserting onto the bony orbit. ${ }^{5}$

Electron microscopy characterizes the truncated-conical shape of the epithelial secretory cells of the acini surrounded by a discontinuous layer of myoepithelial cells. $^{6}$

Microvilli are present on the luminar apical surface. Narrow extensions known as canaliculi are found between adjacent cells. The apical cytoplasm contains a well-developed, rough endoplasmic reticulum and golgi apparatus, as well as a moderate number of mitochondria, free ribosomes, and lipid droplets and vacuoles. A large number of secretory granules dominate the apical and middle regions. These round-to-ovoid, membrane-bound granules may be homogeneous or finely granular and may represent different stages in one or two distinct cell types. The dense granules are mainly serous, but staining for acid mucopolysaccharides shows that mucus is also produced. A small amount of the mucoid layer of the precorneal tear film is of lacrimal gland origin. Plasma cells represent the predominant mononuclear cell population of the normal lacrimal gland. Most of these plasma cells contain gamma A immunoglobulin. Suppressor-cytotoxic T cells, followed by helper T cells, represent the next common cell types found. These findings help support a concept that the lamcrial glandassociated lymphoid belongs to the mucosa system. ${ }^{1,2,7,8}$

\section{Muscles at the lateral canthus}

The muscles within the eyelid in front of the tarsus (pretarsal orbicularis), the protractor muscles, are anchored at the lateral canthal tendon and the lateral palpebral raphe. They travel horizontally across the surface of the upper and lower tarsus, and as they reach the medial canthal area they split into a superficial and deep portion or the head. The deep head of the pretarsal orbicularis muscle from the upper and lower lid inserts on the lacrimal bone at the posterior lacrimal crest behind the sac and in some cases has been referred to as Horner's muscle. An additional strand of orbicularis muscle from the preseptal area in the lower lid inserts on the periosteum, which covers the lacrimal sac and its fossae, it extends from the posterior to the anterior lacrimal crest as described by Jones. ${ }^{4}$ The superficial 
head of the pretarsal orbicularis and preseptal orbicularis fibers insert in a dense conjoined medial canthal tendon anterior to the fundus of the lacrimal sac (Figure 1).

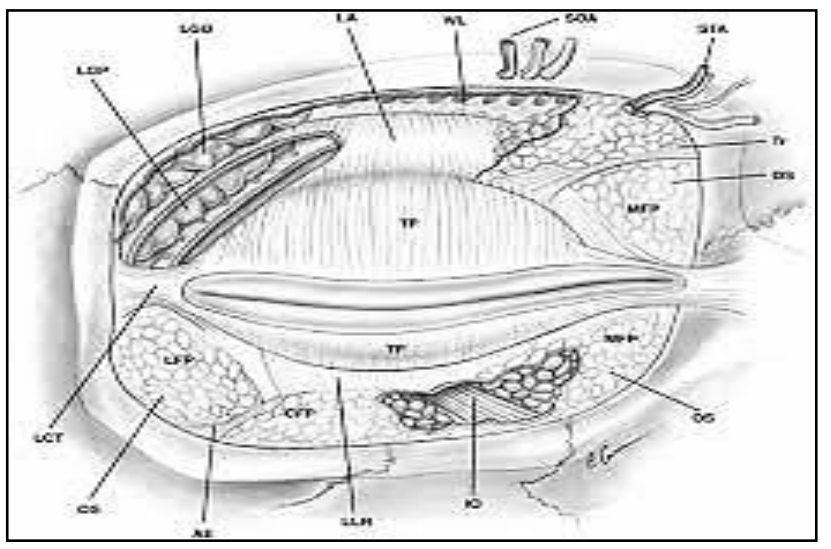

Figure 1: Schematic relations of the lacrimal gland.

\section{Vascularity and lymphatics of the lacrimal gland}

The main blood supply to the gland is through the "lacrimal artery", a branch of the ophthalmic artery and therefore a branch of the internal carotid artery. The lacrimal artery penetrates the gland posteriorly.

Branches of the transverse facial or infraorbital arteries may supply the gland in some patients. Thus connecting the external and internal carotid branches. The lacrimal artery often anastomoses with the anterior division of the middle meningeal artery (external carotid) through the distal tip of the superior orbital fissure. Terminal branches of the lacrimal artery also anastomoses in the eyelid with the anterior deep temporal artery (external carotid). ${ }^{2,10}$

The venous drainage of the gland is usually into the superior ophthalmic vein. The lymphatic drainage of the gland passes to the preauricular (superficial parotid) lymph nodes.

\section{The naso-lacrimal duct system}

The lacrimal duct system is constituted by the superior and the inferior units. Tears first enter the superior unit at the lacrimal punctum. The punctum is a 0.2 to $0.3 \mathrm{~mm}$ opening at the mucocutaneous junction on both the upper and lower eyelids. The punctae of the upper and lower lid are $5 \mathrm{~mm}$ and $6 \mathrm{~mm}$, respectively, lateral to the edge of the medial canthus. The punctae ideally approximate each other on closure of the eyelids .Tears on entering the punctae, flow through the canaliicular system. The $2 \mathrm{~mm}$ long vertical canaliculus extends perpendicular to the eyelid margin and dilates to form the ampulla. At the ampulla, the canaliculus makes a 90-degree turn medially. ${ }^{11}$ The canaliculi then proceed $8 \mathrm{~mm}$ horizontally, following the arc of the eyelid. In $90 \%$ of individuals, the lower and upper canaliculi join proximal to the lacrimal sac, forming a single 3 to $5 \mathrm{~mm}$ long common canaliculus. In $10 \%$, the canaliculi enter the lacrimal sac directly and independently. Proximal to the lacrimal sac, the common canaliculus dilates to form the sinus of Maier. Tissue in-foldings form the valve of Rosenmuller, to partition the common canaliculus from the lacrimal sac. ${ }^{12}$ Thereby prevents reflux through the lacrimal system.

The inferior unit is constituted by the lacrimal sac and the naso-lacrimal duct. The lacrimal sac being superficial to the orbital septum is enclosed by a separate fascia in the lacrimal fosse. The anterior border of the lacrimal fossa is formed by the lacrimal crest of the maxillary bone and the posterior border by the lacrimal crest of the small lacrimal bone. The suture line joining the lacrimal and maxillary bones marks the medial border of the lacrimal fossa. $^{13}$

The site of insertion of the common canaliculus into the lacrimal sac is the seaparating point between the upper and lower units. The fundus of the lacrimal sac is situated above the insertion, and the body below it. The lacrimal sac is 12 to $15 \mathrm{~mm}$ long, 2 to $3 \mathrm{~mm}$ wide, 4 to $6 \mathrm{~mm}$ deep, and is usually in a collapsed state. ${ }^{14}$

The tendinous insertions of the orbicularis muscle bind the lacrimal sac anteriorly and posteriorly, aiding in the movement of tears. Posterior to the sac, the deep heads of the pre-tarsal and preseptal orbicular muscles insert. Anterior to the sac, the superficial heads of the pre-tarsal and preseptal orbicularis muscles insert onto the anterior crest of the lacrimal fossae. Together, these insertions help squeeze the lacrimal sac to move tears forward through the system. ${ }^{15}$

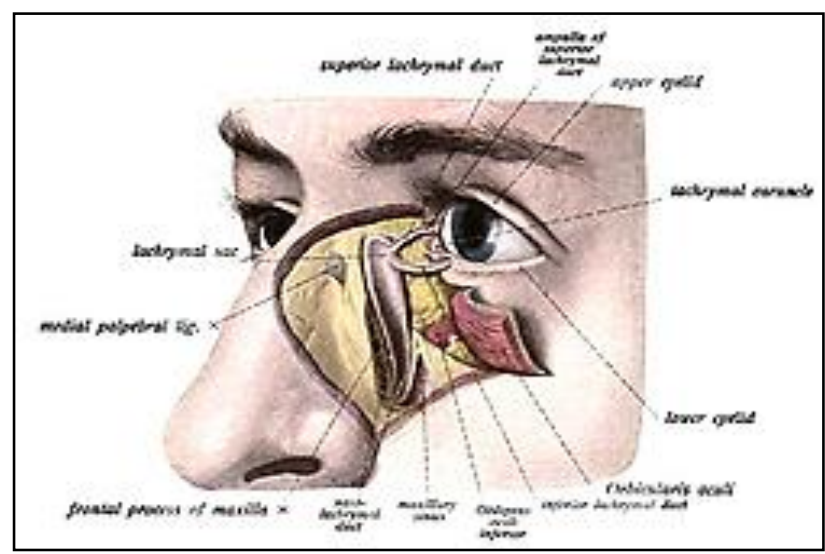

Figure 2: The naso-lacrimal system (cadaveric external dissection).

Infero-posteriorly as visualised in the coronal view, the naso-lacrimal duct descends, from the sac at an angle between 15 and 30 degrees. In the mid-sagittal plane, it descends infero-laterally at an angle of about 5 degrees. The duct is intra-osseous and traverses the maxillary bone. Superiorly the ethmoid bone forms its medial 
border and inferiorly the inferior turbinate. It is about 12 $\mathrm{mm}$ long and 3 to $5 \mathrm{~mm}$ wide. It opens into the inferior meatus at the valve of Hasner. The ostium's location is variable, but it is generally 25 to $35 \mathrm{~mm}$ posterior to the external nares and 4 to $18 \mathrm{~mm}$ above the nasal floor (Figure 2 and 3).

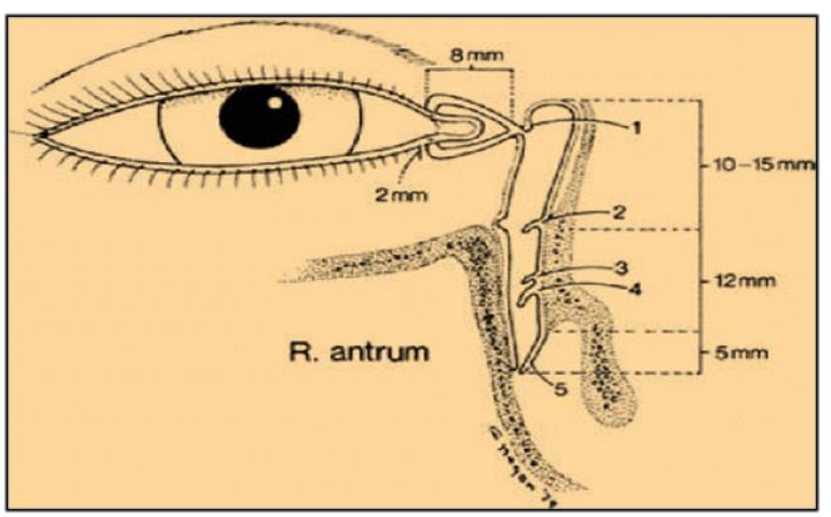

Figure 3: Schematic representation of the nasolacrimal system (punctae, lacrimal sac, nasolacrimal duct). The valves are 1, valve of Rosenmuiller; 2 , valve of Krause; 3, spiral valve of Hyrtl; 4, valve of Taillefer; 5, valve of Hasner or plica lacrimalis.

\section{Embryology of the naso-lacrimal system}

The nasolacrimal duct forms from a cord of ectodermal cells beginning at the seventh week of development. The surface ectodermal cord joins with a growing cord of epithelial cells extending from the nasal cavity. The cord bifurcates in the canthal area, forming early canaliculi. These projections reach the lid margins at 12 weeks. ${ }^{16}$ By seven months' gestation, the papilla and punctual portions of the nasolacrimal duct system are fully formed and patent. The nasal lacrimal duct system canalizes along its extent simultaneously. The last portion to canalize, and the most frequent site of obstruction, is the opening to the inferior meatus of the nasal cavity. After birth, the size of the nasolacrimal duct system continues to increase relative to the surrounding facial structures. The maximum growth occurs in the first six months after birth. (Figure 4). ${ }^{17}$

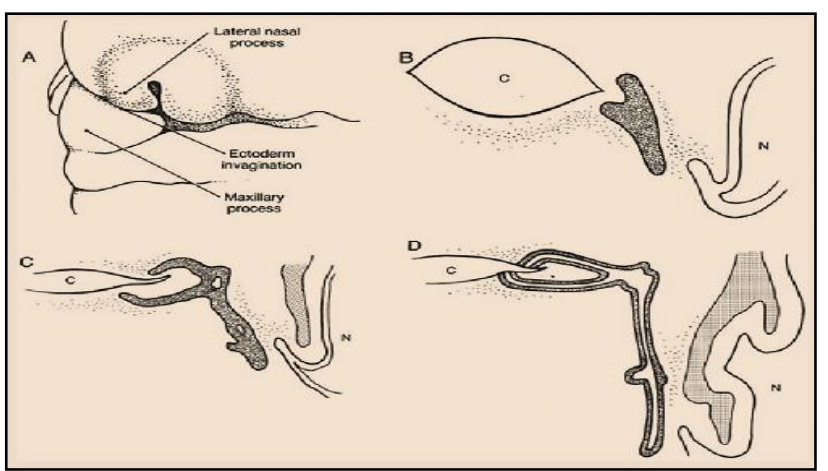

Figure 4: The embryology of the naso-lacrimal system.

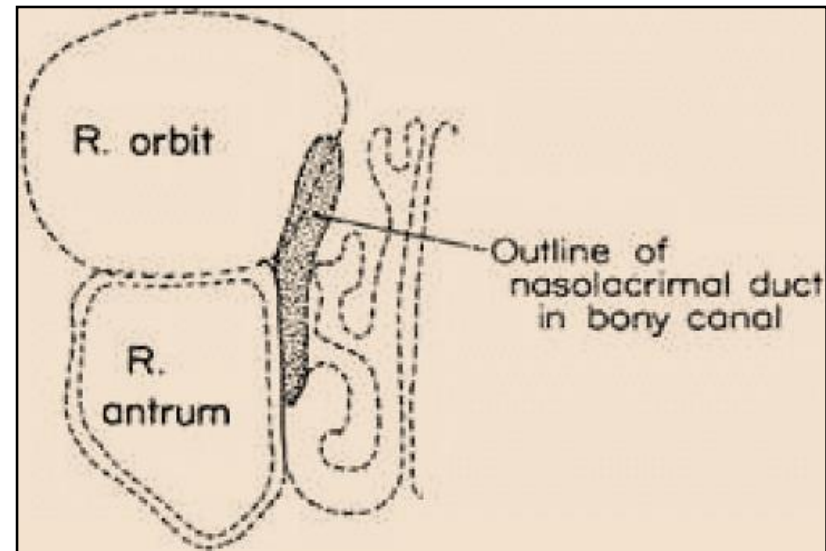

Figure 5: Schematic orientation of the naso-lacrimal duct on coronal view.

\section{Vascularity and lymphatics of the naso-lacrimal system}

The superior and inferior palpebral arteries supply the canaliculi. These are terminal branches of the ophthalmic artery. The angular vessels branching off of the facial artery run superficially and supply the lacrimal sac.

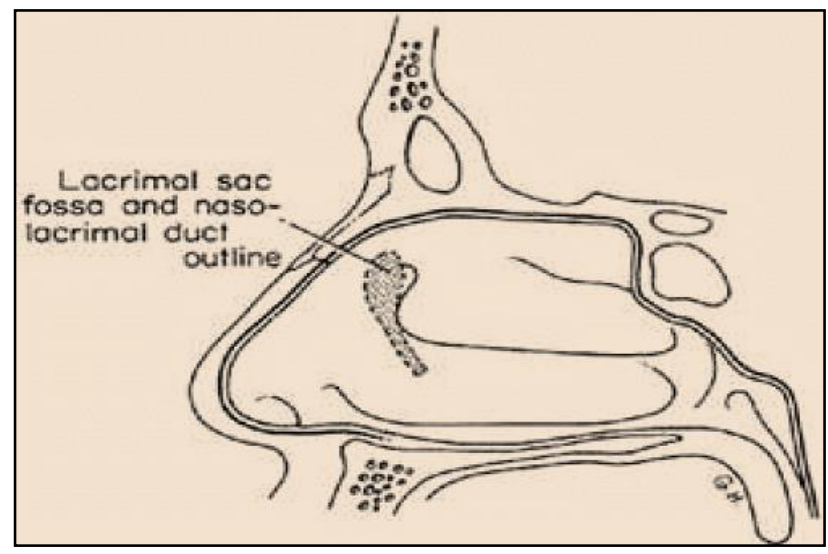

Figure 6: Schematic orientation of the naso-lacrimal duct on saggittal view.

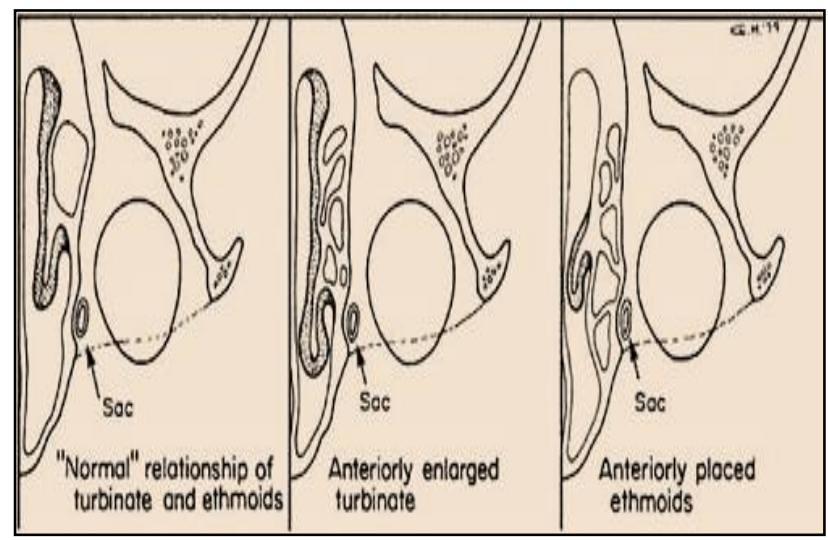

Figure 7: Variations in relationship of the lacrimal sac fosse, the ethmoidal air cells, and the tip of the middle turbinate (axial view). 


\section{Innervation of the lacrimal gland and naso-lacrimal system}

Cranial nerve VII provides motor innervations to the orbicularis muscle. This muscle helps pump tears through the nasolacrimal duct system. The fifth cranial nerve provides sensation superficial to the region of the nasolacrimal duct system.

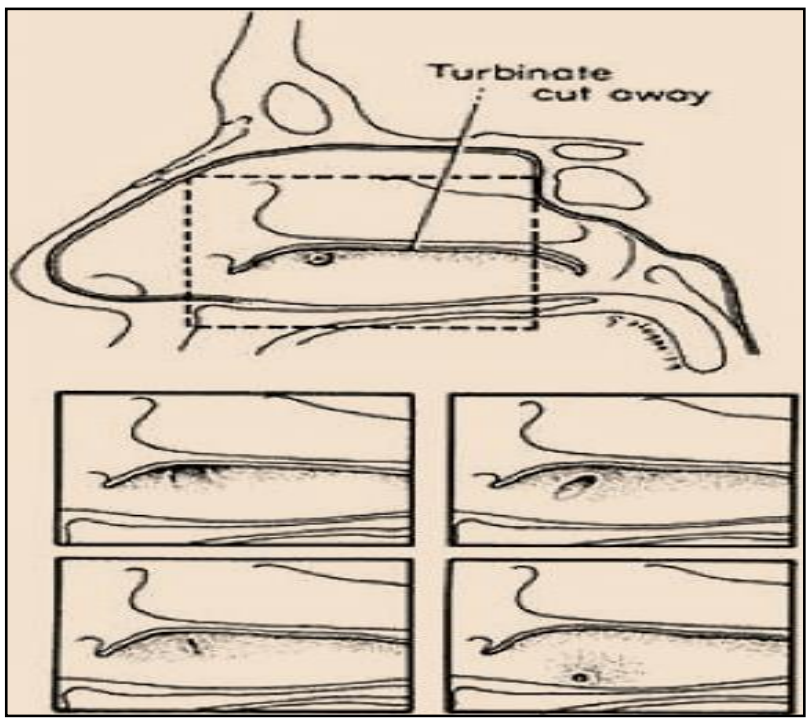

Figure 8: Variations in position and shape of the opening of the end of the nasolacrimal duct under the inferior turbinate (Saggital view).

Source: Adapted from Shaffer JP: Types of Ostia nasolacrimalia in man and their genetic significance. Am J Anat 13:183, 1912.

\section{Musculature of naso-lacrimal system}

The superficial and deep heads of the pre-tarsal tendons of the orbicularis muscle control the pumping action of the lacrimal system. The tendon heads juxtaposed with the cananiculi and the lacrimal sac. Therefore, when the orbicularis muscle contracts, so do the tendon heads, and in concert so does the lacrimal system. This contraction facilitates the capillary action of the lacrimal puncta and lacrimal system that directs the flow of tears to the nasal cavity.

\section{Physiologic variants}

In East Asian descent, the lacrimal fossae or precisely the medial wall of the lacrimal sac is formed predominantly by the thicker maxillary bone instead of the lacrimal bone. ${ }^{18} \mathrm{~A}$ vital point during creation of a neo dacrostome in dacryocystorhinostomy; the maxillary bone being thicker with respect to the lacrimal bone.

In $10 \%$ to $15 \%$ of individuals, the ethmoid air cells may extend anteriorly beyond the posterior lacrimal crest. During a dacryo-cystorhinostomy, avoid aberrant entrance into the air cells.

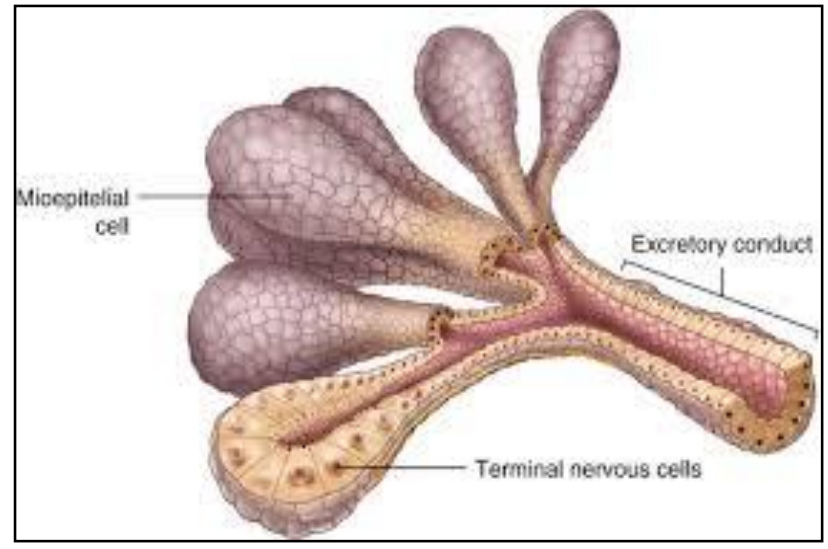

Figure 9: Orientation of the ductal system of the lacrimal gland.

\section{Applied anatomy}

Nasolacrimal duct obstruction is a common problem, especially in children. Up to 1 in 9 newborns have a congenital nasolacrimal duct obstruction. ${ }^{19}$ It most often leads to excessive tearing and epiphora. Probing of the system and sometimes stenting are interventions that open the system and permit tears to flow normally.

It is also a potential site of infection termed dacryocystitis. This condition is more common in children, and in the most severe sequelae can lead to orbital cellulitis. Dacryocystitis can be acute or chronic. It can also be congenital or acquired. When present, there is medial canthal swelling of dacryocystitis, usually below the medial canthal tendon.

Dacrocysto-rhinostomy, external and internal endoscopic approaches are surgical interventions undertaken in chronic dacrocystitis not resolving to medical therapy or syringing.

\section{CONCLUSION}

The individual with excessive tearing can have an atretic, inflammatory or post traumatic obstruction, beginning from the punctae to its inferior meatal exit. The conventional external trans-facial decaping of the posterior wall of the lower naso-lacrimal unit, has given way to the internal trans-nasal intervention. The latter facilitated by the video endoscopic modality. Balloon dilatation using dacro-endoscopy with stenting, though in the trial period may be the future in the lacrimal surgery.

Funding: No funding sources

Conflict of interest: None declared

Ethical approval: Not required

\section{REFERENCES}

1. Welham RA. In: Miller S, ed. Clinical ophthalmology. IOP Publishing Ltd: Bristol (Indian Edn); 1997:391-441. 
2. Wesley RE. Inferior turbinate fracture in the treatment of congenital nasolacrimal duct obstruction and congenital nasolacrimal duct anomaly. Ophthalm Surg. 1985;16:368-71.

3. Ali MJ, Kakizaki H. Embryology of the lacrimal drainage system. In: Principles and Practice of Lacrimal Surgery. Springer, Singapore; 2018:9-18.

4. Jones LT, Wobig JL. Surgery of the eyelids and lacrimal system. Birmingham, Aesculapius; 1976:58.

5. Codère F, Tucker NA, Renaldi B. The anatomy of Whitnall ligament. Ophthalmology. 1995;102(12):2016-9.

6. Nagato T, Yoshida H, Yoshida A, Uehara Y. A scanning electron microscope study of myoepithelial cells in exocrine glands. Cell Tissue Res. 1980;209(1):1-0.

7. Rice DH. Endoscopic intranasal dacryocystorhinostomy: Results in four patients. Arch Otolaryngol Head Neck Surg. 1990;116:1061.

8. Snell RS, Lemp-MA. Clinical Anatomy of the eye, Boston, Blackwell; 1989:114-124.

9. Yamamoto H, Morikawa K, Uchinuma E, Yamashina S. An anatomical study of the medial canthus using a three-dimensional model. Aesth Plast Surg. 2001; 25(3):189-93.

10. Smith B, Bosniak SL. Orbital Trauma Surgery. Complications in Ophthalmic Surgery. 1983:387.

11. Takahashi Y, Kakizaki H, Nakano T, Asamoto K, Ichinose A, Iwaki M. Anatomy of the vertical lacrimal canaliculus and lacrimal punctum: a macroscopic study. Ophthal Plast Reconstr Surg. 2011;27(5):384-6.

12. Tucker NA, Tucker SM, Linberg JV. The anatomy of the common canaliculus. Arch Ophthalmol. 1996;114(10):1231-4.
13. Ali MJ, Schicht M, Paulsen F. Morphology and morphometry of lacrimal drainage system in relation to bony landmarks in Caucasian adults: a cadaveric study. Int Ophthalmol. 2018;38(6):2463-9.

14. Alherabi A, Marglani O, Herzallah I, Shaibah H, Alaidarous T, Alkaff H, et al. Endoscopic anatomy of the lacrimal sac for dacryocystorhinostomy. A cadaveric study. Saudi Med J. 2017;38(3):245-50.

15. Tong J, Lopez MJ, Patel BC. Anatomy, Head and Neck, Eye Orbicularis Oculi Muscle. StatPearls. StatPearls Publishing: Treasure Island (FL); 2020.

16. Sevel D. Development and congenital abnormalities of the nasolacrimal apparatus. J Pediatr Ophthalmol Strabismus. 1981;18(5):13-9.

17. Moscato EE, Kelly JP, Weiss A. Developmental anatomy of the nasolacrimal duct: implications for congenital obstruction. Ophthalmology. 2010;117(12):2430-4.

18. Ye H, Feng Y, Yin S. Anatomy study of the lacrimal bone in dacryocystorhinostomy. J Clin Otorhinolaryngol Head Neck Surg. 2007;21(17):774-6.

19. Sathiamoorthi S, Frank RD, Mohney BG. Incidence and clinical characteristics of congenital nasolacrimal duct obstruction. $\mathrm{Br} \mathrm{J}$ Ophthalmol. 2019;103(4):527-9.

Cite this article as: Munjal M, Munjal S, Vohra H, Prabhakar A, Kumar A, Singh S, et al. Anatomy of the lacrimal apparatus from a rhinologist's perspective- a review. Int J Otorhinolaryngol Head Neck Surg 2021;7:403-8. 